Article

\title{
Remote Sensing Derived Built-Up Area and Population Density to Quantify Global Exposure to Five Natural Hazards over Time
}

\author{
Daniele Ehrlich $^{1, *}$, Michele Melchiorri ${ }^{2}$ (1) , Aneta J. Florczyk ${ }^{1}$ (1), Martino Pesaresi ${ }^{1}$ (1), \\ Thomas Kemper ${ }^{1}$, Christina Corbane ${ }^{1}$, Sergio Freire ${ }^{1}$ (D), Marcello Schiavina ${ }^{1}$ (D) \\ and Alice Siragusa ${ }^{3}$ \\ 1 European Commission-Joint Research Centre, Disaster Risk Management Unit, TP. 267, Via E. Fermi 2749, \\ 20127 Ispra, Italy; aneta.florczyk@ec.europa.eu (A.J.F.); martino.pesaresi@ec.europa.eu (M.P.); \\ thomas.kemper@ec.europa.eu (T.K.); christina.corbane@ec.europa.eu (C.C.); \\ sergio.freire@ec.europa.eu (S.F.); marcello.schiavina@ec.europa.eu (M.S.) \\ 2 Piksel s.r.l, Via Breda 176, 20126 Milano, Italy; michele.melchiorri@piksel.com \\ 3 European Commission-Joint Research Centre, Territorial Development Unit, TP. 263, Via E. Fermi 2749, \\ 20127 Ispra, Italy; alice.siragusa@ec.europa.eu \\ * Correspondence: daniele.ehrlich@ec.europa.eu; Tel.: +39-332-78-9384
}

Received: 20 June 2018; Accepted: 24 August 2018; Published: 30 August 2018

\begin{abstract}
Exposure is reported to be the biggest determinant of disaster risk, it is continuously growing and by monitoring and understanding its variations over time it is possible to address disaster risk reduction, also at the global level. This work uses Earth observation image archives to derive information on human settlements that are used to quantify exposure to five natural hazards. This paper first summarizes the procedure used within the global human settlement layer (GHSL) project to extract global built-up area from 40 year deep Landsat image archive and the procedure to derive global population density by disaggregating population census data over built-up area. Then it combines the global built-up area and the global population density data with five global hazard maps to produce global layers of built-up area and population exposure to each single hazard for the epochs 1975, 1990, 2000, and 2015 to assess changes in exposure to each hazard over 40 years. Results show that more than $35 \%$ of the global population in 2015 was potentially exposed to earthquakes (with a return period of 475 years); one billion people are potentially exposed to floods (with a return period of 100 years). In light of the expansion of settlements over time and the changing nature of meteorological and climatological hazards, a repeated acquisition of human settlement information through remote sensing and other data sources is required to update exposure and risk maps, and to better understand disaster risk and define appropriate disaster risk reduction strategies as well as risk management practices. Regular updates and refined spatial information on human settlements are foreseen in the near future with the Copernicus Sentinel Earth observation constellation that will measure the evolving nature of exposure to hazards. These improvements will contribute to more detailed and data-driven understanding of disaster risk as advocated by the Sendai Framework for Disaster Risk Reduction.
\end{abstract}

Keywords: remote sensing; natural hazards; exposure; disaster; earthquakes; floods

\section{Introduction}

Exposure is reported to be the biggest determinant of disaster risk [1] and the disastrous effects of natural hazards on communities are widely broadcasted through the media but the occurrence of disasters is not always well understood, due to a lack of data. Disaster science and disaster 
risk management practices are continuously evolving and improving the availability of datasets. The capacity to derive information from these data is used in several phases of the disaster risk management cycle: to organize emergency response and relief to people affected; to provide information to decision makers and the crisis management operators that manage resources and logistical infrastructure to support reconstruction and rehabilitation; and also to reduce potential future hazard impact through disaster risk reduction strategies, by taking more risk informed decisions. In fact, at international levels the Sendai Framework for Disaster Risk Reduction [2] calls for understanding risk (Priority 1) and its components, and to implement measures that can reduce future losses. Reducing the number, frequency, intensity, and duration of disasters is also an essential component of the 2030 Agenda for Sustainable Development to which also the Paris Agreement to Climate Change [3] and the New Urban Agenda [4] contribute to.

Exposure is defined based on hazard information. This work focuses on assessing globally the geographical location of exposure of people and built-up areas over time to a selected number of natural hazards. This work is for use in global analysis and for data poor regions of the world. In fact, while many countries, especially high income countries, maintain national georeferenced databases of building stock and population, many others, often low income and data poor ones, lack of a basic information infrastructure to be used in crisis management. Global data may be a first remedy to fill this gap on the geographical location of exposure. Their vulnerability of the exposed assets to a given hazard - the degree to which they will experience harm as a result of the impact of the hazards $[5,6]-$ is not addressed in this paper as vulnerability is defined from variables that can be only partially derived from remote sensing data [7] and thus outside of the scope of this paper.

Satellite remote sensing is considered the key technology to globally generate geographical location exposure data. Early attempts to quantify global exposure date back to 2005 in the first effort to map disaster hotspots [8]. That early work used single date gridded population densities in combination with other variables available at global level from compilation of socio-economic data at different form of spatial aggregation. It highlighted the need to generate data on the built-up environment also for use in disaggregating variables collected at coarse scale. Satellite imagery archives started to be used to map urban areas or land cover that typically included urban as one land cover class. The early global products with urban land use classes originating from moderate resolution satellite imagery ranging from 300 to $1000 \mathrm{~m}$ spatial resolution included Advanced Very High Resolution Radiometer, AVHRR [9], Defense Mapping Satellite Program's Operational Linescan System (DMSP/OLS night time lights [10] and Moderate Resolution Imaging Spectrometer (MODIS) [11]. However, the estimates of urban areas from these studies varied significantly [11], and due also to a lack of validation based on a global reference dataset, these early datasets were considered preliminary products awaiting for finer resolution datasets to become available. Urban maps are now derived also from finer resolution satellite image archives. For example TerraSAR-X imagery was used to derive the Global Urban Footprint (GUF) [12] that provides a fine scale global map of urban areas from SAR Technology for a single epoch. A recent multi-class global land cover map derived from Landsat includes the "urban class" that captures also the built-environment globally [13].

The image archives from these sensors have also been used to analyze changes in built-up area over time [14] on regional and local applications. For example, DMSP/OLS together with Satellite Pour l'Observation de la Terre (SPOT) VEGETATION (SPOT-VGT) data were used to detect changes of settlement between 1998 and 2008 in India [15]. MODIS 500 at $500 \mathrm{~m} \times 500 \mathrm{~m}$ spatial resolution images were used to map urban areas in East Asia from 2000 to 2010 [14,16]. At local level Landsat image archives have been, and still are, extensively used to map urban spatial extent and growth often in multi-city studies [17] or the process of urbanization over decades and with global coverage [18]. An extended review on land cover mapping for urban applications is available from [19].

The rapidly developing archives of global very high resolution imagery (VHR) hold the wealth of built-up information-down to the building footprint level-for future global exposure layers. Extracting information from VHR imagery is high on the agenda of VHR image providers: the topic of image 
processing research includes different techniques such as association rule learning and support vector machine [20], combined used of GIS and automatic pattern recognition [21], or the combination of remote sensing with statistical inferencing [22]. The scientific literature focusing on exposure mapping from VHR is very large, even with dedicated journal issues [23], and it is introducing a promising innovation that exploits the multi-resolution mapping, particularly in seismic exposure mapping studies [24-26] at regional level, but also to support the Global Exposure Model [27]. The extraction of built-up from VHR-typically in the form of building footprints-is mostly used in case studies at the city level. These studies typically include also the vulnerability assessment [28] conducted by the identification of buildings structural characteristics, including building height. The built-up extraction techniques and procedures from VHR used in local case studies have not yet shown to be applicable to derive global consistent exposure datasets as addressed in this paper. In addition, global VHR archives are not yet available as open source data that can be used to generate global exposure layers.

This work describes the use of the Landsat satellite image archive-a consistent and open source dataset depicting the Earth surface over the last 40 years (from about 1975 to 2015)—to map built-up areas and derive population density. This work builds on previous research that derived global built-up area and population density at fine resolution for four decades dating back to 1975 [29-31]. The datasets aimed to be consistent in space and time and then allowing spatial comparison as well as the analysis of spatial growth for all settlements of the world. The methodology for producing the global human settlement layers is repeatable in space and in time. It is also suited to be used on imagery that will be collected from future missions including that of Sentinel [32] to allow updating global built up maps. The temporal depth of the datasets was deemed appropriate for the analysis of the variation of exposure to natural hazards. The change of exposure over time is key to address the issue of disaster risk management, the topic of the special issue. This work conducted within the Global Human Settlement Layer project (GHSL) also delivers population density grids, which are used in this research work for assessing global population exposure. The exposure of built-up area and population is computed using five hazard layers made available through the Global Assessment Report on Disaster Risk Reduction 2015. The data are briefly summarized in the following sections. This research is not a cross-hazard analysis as hazards are computed with different return periods. It is also not a multi-hazard exposure analysis that requires the analysis of cascading effects between hazards that are out of scope of this work. The main goals of this research are to show the absolute change of exposure for single hazards over time and provide a general assessment of the extent of built-up area and population globally exposed to five natural hazards for selected RPs.

In this paper we first summarize the production of the GHSL layers that are the basis of this research. We describe then the methodology for quantifying exposure with the GHSL data using hazard maps, and we analyze and present the global exposure of population and built-up areas to five natural hazards. Results are aggregated mostly at national level. The GHSL layers datasets are available for download at <http:/ / ghsl.jrc.ec.europa.eu/> and part of the analysis has been graphically documented in the Atlas of the Human Planet, 2017 [33].

\section{Data and Methods}

The data and methods used in this research work are graphically summarized in Figure 1. At the core of this research is the mapping of global built-up areas (GHS-BUILT) from the Landsat image archives as described in Section 2.1.1. The GHS-BUILT layer is then used in combination with global population census data to derive GHS-POP, a gridded population density described briefly in Section 2.1.2. The two variables are referred to as human settlement layers.

To address the topic of this special issue the two human settlement datasets are then combined with global hazard layers described in Section 2.1.3 to estimate potential exposure to each hazard. In Figure 1 the rows represent the human settlement layers available for four epochs; the columns represent the hazards analyzed, and the intersection between built-up area and population-the global exposure layers-resulting in four exposure layers of population and four exposure layers of built-up 
area to each of the five hazards. For discussion purposes the potential exposure information is aggregated at the national level using a country border layer.

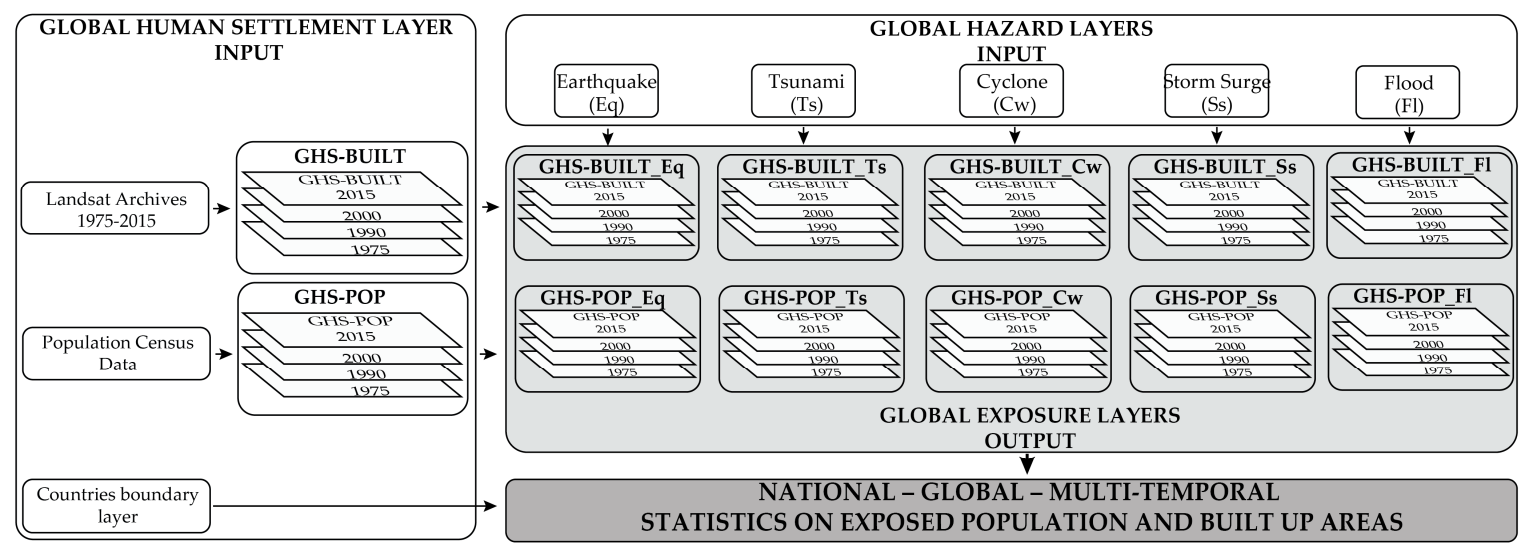

Figure 1. Schematic overview of all input datasets (white boxes), Global Human Settlement and hazard maps, and the resulting exposure datasets produced (shaded boxes).

\subsection{Input Data}

The section below summarizes the production of the global built-up and the global population layers. This section also describes the characteristics of the five global hazard layers used herein. Finally, it briefly describes the global administrative unit layer used to aggregate the exposure statistics at national and global level.

\subsubsection{Global Built-Up Area}

The global built-up area layers are produced within the Global Human Settlement Layer (GHSL) image processing framework. The GHSL framework produces new global spatial information, evidence-based analytics and knowledge describing the human presence on the planet over time, operating in an open and free data and methods access policy (open input, open method, open output). It includes models, tools, and datasets developed to process satellite imagery, including that of Landsat and to perform geo-spatial analysis [29]. Landsat historical data are available as an open source dataset from the Global Land Cover Facility (http:/ /www.landcover.org/) [34]. Data are available as geo-coded image products. The Landsat collection includes images obtained from different sensors with different spatial resolutions: the Multi Spectral Scanner (MSS) and the Thematic Mapper 4-5 record at $75 \mathrm{~m} \times 75 \mathrm{~m}$ resolution, the Enhanced Thematic Mapper (ETM) on Landsat 7 at $30 \mathrm{~m} \times 30 \mathrm{~m}$, and the Operational Land Imager (OLI) with spectral bands at $30 \mathrm{~m} \times 30 \mathrm{~m}$ resolution, panchromatic bands at $15 \mathrm{~m} \times 15 \mathrm{~m}$; and the thermal bands from the Thermal Infrared Sensor (TIRS) at $100 \mathrm{~m} \times 100 \mathrm{~m}$ that are resampled for distribution at $30 \mathrm{~m} \times 30 \mathrm{~m}$.

The Landsat archive is well suited to extract spatially and temporally consistent information and the spectral bands maintain a consist viewing geometry with stable Instantaneous Field Of View (IFOV) referred herein as spatial resolution of imagery [35]. That stable viewing geometry and viewing precision is a fundamental image parameter for detecting and mapping small features such as building structures that form human settlements and changes of settlement spatial extent in time. Radiometric resolution has improved also over time providing a higher dynamic range that increases the ability to discriminate between landscape structures. The GHSL image processing algorithm processed 32,808 images organized in four collections that group the set of images based of four time spans referred as epochs [36]. The 1975, 1990, 2000, and 2014 epochs included 7588, 7357, 8756, and 9098 images, respectively. The images for epochs 1975-2000 were obtained from the Global Land Cover (GLCF) 
facility [36], while an ad-hoc Landsat 8 collection for 2013/2014 was assembled from the Earth Explorer website of the United States Geological Survey.

Big data processing requires new approaches, improving on the standard paradigm for information extraction from remote sensing [37]. This is due to the stability and calibration of the signal (standardization), the volume of data to be processed and the processing speed that is required in operational mode. In fact, until recently machine learning approaches have been mostly used for processing small size datasets and a limited number of features. These methods are impractical in a global setting for at least two important reasons: the heterogeneity of the images when considering the image archive to process and the lack of representative training sets. A new strategy was attempted in this work.

The GHSL image classification uses the Symbolic Machine Learning (SML) methodology [38]. SML is based on image data quantization sequencing and association analysis. The image data sequencing aims to reduce the number of features to process. The association analysis links the set of reference data that acts as training data and the feature space used in the sequencing. The association is measured as a confidence index referred herein as Evidence-based Normalized Differential Index (ENDI) that provides a continuum of positive and negative values ranging from -1 to 1 . ENDI expresses strength of association between the image data layers and the reference data. Values close to 1 indicate that the feature sequence is strongly associated with the image class of interest-the built-up in our case-while values close to -1 indicate that the feature is strongly associated with classes other than built-up. The classification is conducted for each image separately and the resulting classification maps are then combined through mosaicking.

The global multi-temporal layers reporting on built-up presence are produced and made available at the native spatial resolution of $38 \mathrm{~m} \times 38 \mathrm{~m}$ (Figure 2). For use in in this research the data are also aggregated at spatial resolution of $250 \mathrm{~m} \times 250 \mathrm{~m}$ in World Mollweide projection (EPSG 54009) referred to as GHS-BUILT spatial grid. The spatial grid contains values coded between 0 and 1 representing the built-up area over the total area of the grid cell.

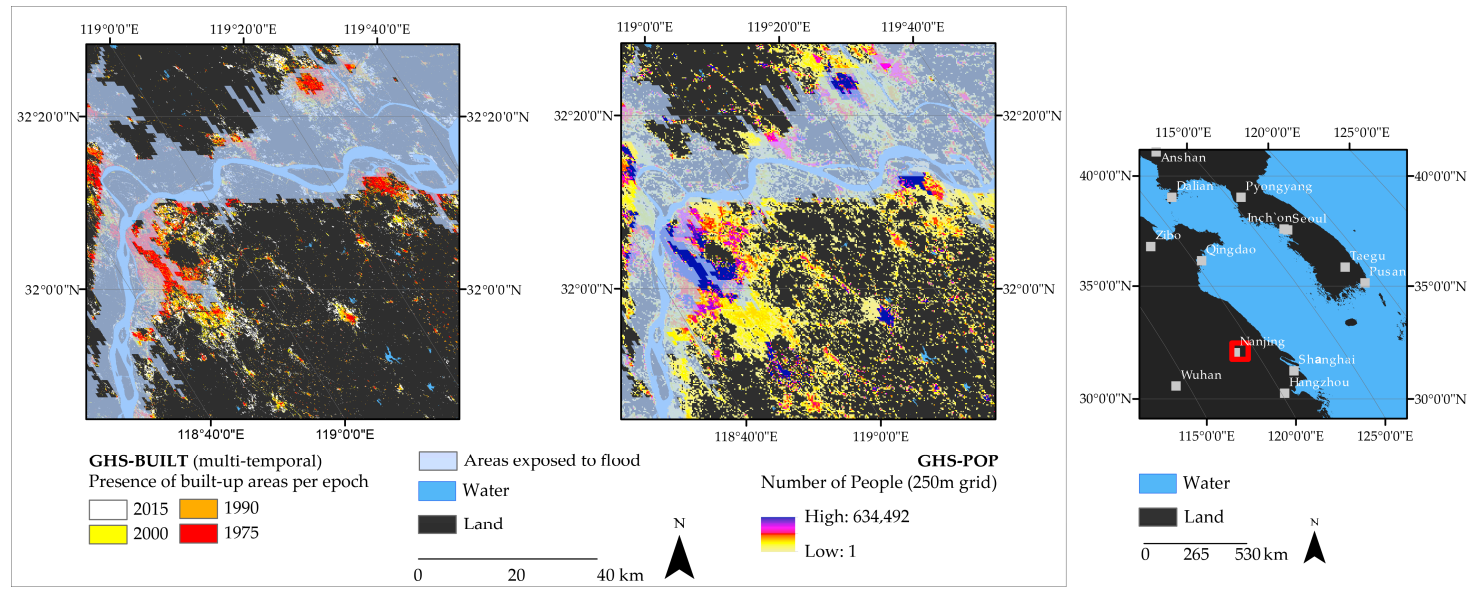

Figure 2. GHS-POP (population density), and GHS-BUILT (multi-temporal built-up density) layers overlaying with the flood hazard map over Nanjing (China). The image shows the built-up detected in recent epochs (white in 2015 to red in 1975) lay in areas exposed to floods.

\subsubsection{Global Population Density}

The global population distribution grids described in this work are produced from a combination of built-up area and population estimates available by census or administrative unit from the Gridded Population of the World (GPW) project [39]. The GPW project assembles, from a number of data providers, a global census-based population database that combines spatially explicit administrative boundaries and corresponding resident population counts for use in population disaggregation [40]. 
For each of the 12,000,000 census units in the GPW database, population counts were estimated for reference years matching those in the GHS-BUILT dataset (i.e., 1975-1990-2000-2015). Producing this population database involves harmonizing disparate census in the spatial and temporal domains, namely by interpolating and extrapolating population counts from at least two available census dates for each country [41]. These estimates are then disaggregated to each cell in GHS-BUILT in proportion to the built-up density, per matching epoch, thus significantly sharpening the census data, while preserving the source counts [31]. Quality assurance was conducted to ensure validity of the approach and results [31]. The population density dataset is made available as global grids of $250 \mathrm{~m} \times 250 \mathrm{~m}$ resolution for the four epochs $(1975,1990,2000$, and 2015), and is currently the most detailed and consistent time series depicting contemporary population distribution and density.

\subsubsection{Hazard Maps}

The hazard data used in this work are: three global probabilistic hazard layers available as open source, and two probabilistic hazard maps produced at the Joint Research Centre (Table 1). The Global Seismic Hazard map (GSHAP) is a global seismic hazard map which depicts Peak Ground Acceleration with $10 \%$ chance of exceeding in 50 years when calculated over a return period of 475 years [42]. We used this map converted into classes of the Modified Mercalli Intensity (MMI) scale based on the work [43], and grouped in four intensity classes (http://preview.grid.unep.ch/index.php?preview= data\&events=earthquakes\&evcat=11\&lang=eng). The resulting seismic hazard map was available as a raster at 6 arc-min spatial resolution in WGS-84 in support to the Global Assessment Report on Disaster Risk Reduction-GAR 2013 [1]. The hazard map depicts the areas exposed to moderate or more intense shaking (i.e., level 5 or higher).

Table 1. Comprehensive overview of the hazard layers used in this study.

\begin{tabular}{|c|c|c|c|c|c|c|}
\hline $\begin{array}{l}\text { Natural } \\
\text { Hazard }\end{array}$ & Input Dataset & Source & Semantic Content & $\begin{array}{l}\text { Hazard Processing } \\
\text { Rules Applied } \\
\text { (Resampled to } \\
\text { Mollweide } \\
\text { Projection } 250 \mathrm{~m} \\
\text { Grid Cells) }\end{array}$ & $\begin{array}{c}\text { Input Data } \\
\text { Type }\end{array}$ & $\begin{array}{c}\text { RP } \\
\text { (Years) }\end{array}$ \\
\hline Earthquake & MMI-GSHAP & GAR 2013 & $\begin{array}{l}\text { Modified Mercalli } \\
\text { Intensity (MMI) } \\
\text { scale }\end{array}$ & $\begin{array}{c}\text { Classification } 1-8 \text {; } \\
\text { (1) hazard mask: } x \geq 5\end{array}$ & $\begin{array}{l}\text { Raster, } 6 \text { arc-min } \\
\quad(\sim 11 \mathrm{~km}) \\
\text { WGS-84 }\end{array}$ & 475 \\
\hline Tsunami & Tsunami Run-up & GAR 2015 & $\begin{array}{l}\text { Areas potentially } \\
\text { affected by } \\
\text { tsunami run-up }\end{array}$ & $\begin{array}{c}\text { Binary map }[0,1] \\
\text { (1) hazard mask: } x>0\end{array}$ & $\begin{array}{c}\text { Vector, } 31.5 \\
\text { arc-sec }(\sim 1 \mathrm{~km}) \\
\text { WGS-84 }\end{array}$ & 500 \\
\hline Flood & Flood map & $\begin{array}{c}\text { JRC Global } \\
\text { Flood } \\
\text { Awareness } \\
\text { System } \\
\text { GloFAS }\end{array}$ & $\begin{array}{l}\text { Extent of flooded } \\
\text { areas (water depth } \\
10 \mathrm{~cm} \text { or more) }\end{array}$ & $\begin{array}{l}\text { Depth of the flood } \\
{[\mathrm{m}]: x \geq 0.01} \\
\text { (1) hazard mask: } x>0\end{array}$ & $\begin{array}{l}\text { Raster, } 30 \text { arc-sec } \\
(\sim 1 \mathrm{~km}) \text { WGS-84 }\end{array}$ & 100 \\
\hline $\begin{array}{l}\text { Cyclone } \\
\text { Wind }\end{array}$ & $\begin{array}{l}\text { JRC-GAR, wind } \\
\text { category }\end{array}$ & $\begin{array}{l}\text { GAR } 2015 \text {, } \\
\text { adapted by } \\
\text { JRC }\end{array}$ & $\begin{array}{l}\text { Wind speed from } \\
\text { Saffir-Simpson } \\
\text { Hurricane Wind } \\
\text { Scale }\end{array}$ & $\begin{array}{l}\text { Classification } 1-5 \text {; } \\
\text { (1) reclassify into } \\
\text { hazard zones SS1-2 } \\
\text { and SS3-5 }\end{array}$ & $\begin{array}{l}\text { Raster, } 30 \text { arc-sec } \\
(\sim 1 \mathrm{~km}) \text { WGS-84 }\end{array}$ & 250 \\
\hline $\begin{array}{c}\text { Cyclone } \\
\text { Storm Surge }\end{array}$ & $\begin{array}{c}\text { JRC-GAR, } \\
\text { inundated area }\end{array}$ & $\begin{array}{l}\text { GAR 2015, } \\
\text { adapted by } \\
\text { JRC }\end{array}$ & $\begin{array}{l}\text { Areas potentially } \\
\text { inundated by } \\
\text { storm surge }\end{array}$ & $\begin{array}{c}\text { (1) the inundated } \\
\text { areas based on point } \\
\text { sea-level surge and } \\
\text { elevation SRTM v4.1; } \\
\text { (2) hazard map from } \\
x>0\end{array}$ & $\begin{array}{l}\text { Vector (point), } \\
\text { WGS-84 }\end{array}$ & 250 \\
\hline
\end{tabular}

The tsunami hazard map-referred to as Tsunami Run-up map-refers to the low lying coastal land that may be inundated by tsunamis, and it was calculated with a return period of 500 years. It was derived by estimating the wave height and developing an inundation model based on SRTM data [44]. These data, available as a raster at 31.5 arc-sec $(\sim 1 \mathrm{~km})$ spatial resolution in WGS-84, were used for 
the GAR 2015 report [1]. The hazard layer used in this work is a binary map depicting the extent of potentially inundated areas by tsunamis.

The hazard map used for tropical cyclones represents a rating from 1 to 5 of hurricanes expressed in the Saphir-Simpson Hurricane Wind rating Cyclones in five categories, as follows: category 1, $119-153 \mathrm{~km} / \mathrm{h}$; category $2,154-177 \mathrm{~km} / \mathrm{h}$; category 3, 178-208 km/h; category $4,209-251 \mathrm{~km} / \mathrm{h}$; and category 5, $252 \mathrm{~km} / \mathrm{h}$ or higher. Hurricanes reaching Category 3 and higher are considered major hurricanes (potentially causing significant loss of life and damage), while category 1 and 2 storms are still dangerous and require preventive measures. This map has been derived from the dataset on Tropical Cyclonic Wind-a product of a probabilistic model calculating the gasp wind speed per observation unit over a 250 year return period. This dataset, available as a raster at $30 \operatorname{arc}-\sec (\sim 1 \mathrm{~km})$ spatial resolution in WGS-84, is accompanying the GAR 2015 [1] report. In this analysis, we have grouped Cyclone intensities 1-2, and 3-5 into two separate classes.

The probabilistic hazard map on tropical cyclone storm surge has been produced at the JRC-EC for a return period of 250 years. The baseline data is the global GAR 2015 dataset on wave height at point locations at the coast. The global elevation model, SRTM data set [44], was used to derive a potential surge inundation map using the method described in [45]. The resulting hazard map used is a binary map depicting the extent of potentially inundated areas.

Finally, we used the flood map Global Flood Awareness System (GloFAS) with 100 years return period generated in [46], and made available as a raster at 30 arc-sec $(\sim 1 \mathrm{~km})$ spatial resolution in WGS-84. We have used the 100 years return period over other return periods as that time span is the one used to communicate flood risk to decision makers that are implementing decision risk reduction measures [47]. The hazard layer used in this work is a binary map depicting flooded areas with water at least $10 \mathrm{~cm}$ deep.

\subsection{Methodology}

This work uses geospatial analysis techniques to overlay, intersect in technical terms, the hazard maps with GHSL layers, and conduct zonal analysis to derive statistics on built-up surface and population per hazard zone. The GHSL represent exposure layers when crossed with the hazard layers (Figure 1). We intersect each hazard with the four population layers referred to as GHS-P_1975-GHS-P_2015 in its four epochs, and the GHS-BUILT in its 4 epochs. The resulting exposure layers include for each hazard GHS_P_Hazard_1975,1990,2000,2015; and GHS_BU_Hazard_1975,1990,2000,2015_Ts, where "Hazard" includes Earthquake (EQ), Tsunamis (TS), Cyclone Winds (CW), Sea level surge (Ss) and Floods (Fl). The zonal analysis is conducted at the resolution of $250 \mathrm{~m} \times 250 \mathrm{~m}$ grid cells.

For the purpose of this work we aggregate the exposure statistics at the national level using Global Administrative Boundaries Model (GADM (https://gadm.org/)) available as open source datasets. However, as the information is recorded at $250 \mathrm{~m} \times 250 \mathrm{~m}$ cells, the analysis may be conducted at local level for the area of interest. This can be administrative units, hazard impact areas, or hazard risk areas. For example, Figure 2 illustrates one heavily settled area exposed to flooding with 100-year return period.

\section{Results}

The potential exposure of built-up areas and population to each of the five hazards over time is assessed at the grid cell level. For each hazard we use only one return period because, except for floods, the hazard map was available only for one return period. For practical reasons, we present the results of our analysis by aggregating the exposure data at national and global scale also because some hazard map are coarser than the exposure map.

\subsection{Global Exposure Statistics}

Figure 3 shows the extent of global built-up areas and population exposed to five hazards over time. Table 2 reports the main results of this study. The analysis shows that nearly one third of the 
global population and built-up area are located in seismic areas that could exceed the MMI level 5. Tsunamis potentially affect an order of magnitude less built-up and people than the earthquakes that generated them. In 2015, more than 1.5 billion people were living in cyclone wind prone areas while the sea level surge caused by cyclones that affects coastal areas may have just impacted over an order of magnitude less people (160 million). Floods hazard shows the highest rate of increase of exposure across the four epochs growing from $28.6 \mathrm{~km}^{2}$ to $80.4 \mathrm{~km}^{2}$ of built-up areas and from 518.0 million to 1037.2 million people. The proportion of potential exposed population and built-up area has increased for all hazards over time. For example, there were 1 billion less people exposed to seismic hazard in 1975 than in 2015. The results of the analysis are presented in the following sections by grouping hazards according to the physical processes that generate them: earthquakes and tsunamis, tropical cyclones and storm surge, and floods.

a Built-up areas exposed to five hazards

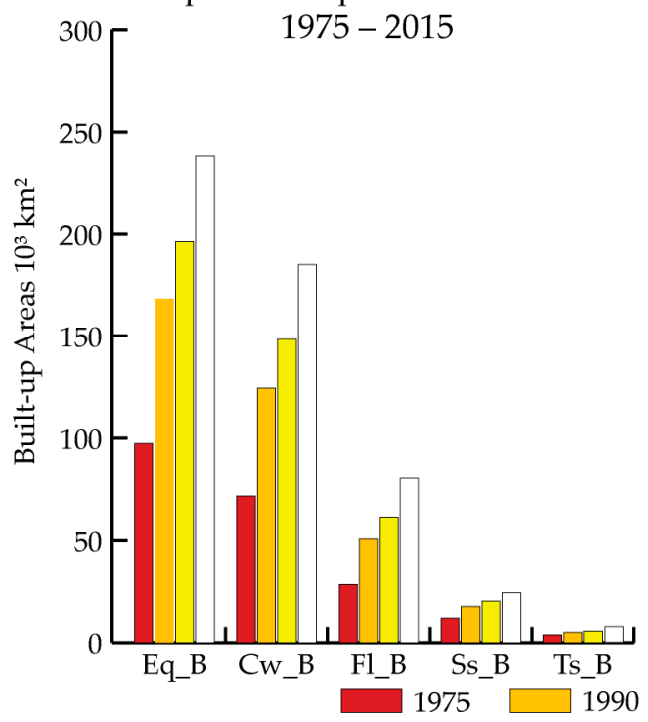

b Population exposed to five hazards

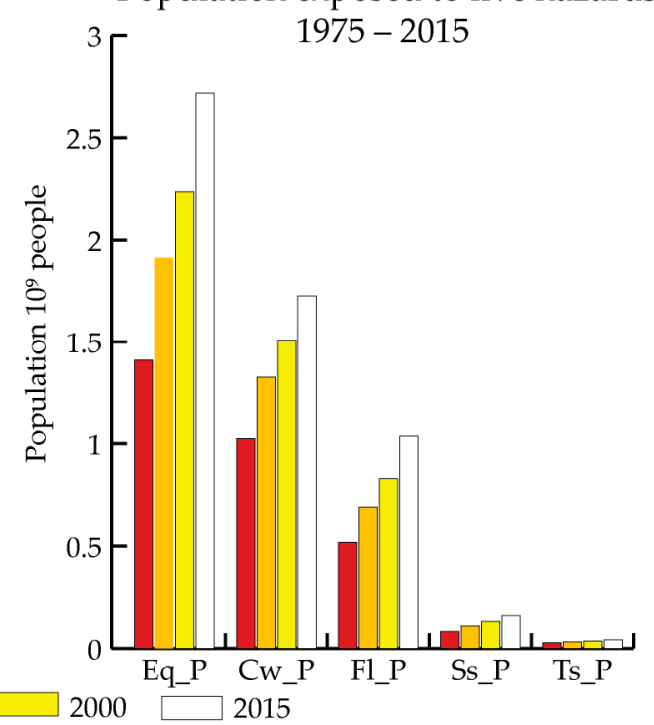

Figure 3. Built-up (a) and population (b) exposed to hazards: earthquakes (Eq), Tsunamis (Ts) with return period of 475 years; Cyclone winds $(\mathrm{Cw})$ and Sea level surge (Ss) with return periods of 250 years; and Floods $(\mathrm{Fl})$ with return periods of 100 years.

Table 2. Global figures of built-up areas and population exposed to the different hazards per epoch.

\begin{tabular}{ccccccccc}
\hline \multirow{2}{*}{ Hazards } & \multicolumn{3}{c}{$\begin{array}{c}\text { Exposed Built-Up Areas per Hazard } \\
\left(\mathbf{1 0}^{\mathbf{3}} \mathbf{~ k m}^{\mathbf{2}} \mathbf{)}\right.\end{array}$} & \multicolumn{3}{c}{$\begin{array}{c}\text { Exposed Population per Hazard } \\
\left(\mathbf{1 0}^{\mathbf{6}} \text { People) }\right.\end{array}$} \\
\cline { 2 - 9 } & $\mathbf{1 9 7 5}$ & $\mathbf{1 9 9 0}$ & $\mathbf{2 0 0 0}$ & $\mathbf{2 0 1 5}$ & $\mathbf{1 9 7 5}$ & $\mathbf{1 9 9 0}$ & $\mathbf{2 0 0 0}$ & $\mathbf{2 0 1 5}$ \\
\hline Earthquake (Eq) & 97.3 & 168.3 & 196.5 & 238.2 & 1409.3 & 1911.9 & 2235.7 & 2717.8 \\
Cyclone Wind (Cw) & 71.6 & 124.3 & 148.4 & 185.1 & 1025.2 & 1326.4 & 1508.1 & 1726.3 \\
Flood (Fl) & 28.6 & 50.8 & 61.2 & 80.4 & 518.0 & 690.4 & 828.2 & 1037.2 \\
Storm Surge (Ss) & 11.9 & 17.6 & 20.3 & 24.3 & 82.6 & 109.7 & 132.6 & 161.5 \\
Tsunami (Ts) & 3.9 & 5.1 & 5.7 & 6.5 & 27.6 & 31.8 & 36.5 & 41.7 \\
\hline
\end{tabular}

\subsubsection{Exposure to Earthquakes and Tsunamis}

Earthquakes generally occur along geological faults where rupture occurs and seismic waves propagate away from rupture points with attenuated shaking intensity. The intersection with the earthquake intensity and population layers shows human population living in areas that may experience shaking intensity above the 5 Modified Mercalli Intensity (MMI) scale the intensity above which infrastructural damages may occur. 
The results show that in 2015 approximately 50 million people lived in regions with seismic risk potentially exceeding magnitude 9 in MMI Scale (Figure 4). The total number of people exposed to potentially damaging earthquakes-those exceeding 5 MMI Scale-account for 37\% of the global population and live in 145 countries concentrated in Asia, Pacific Islands, Middle East Asia, Eastern Europe, and the western part of the Americas. The population potentially exposed to earthquakes doubled in the last 40 years, while the built-up surface increased by $145 \%$ during the same period, from 97,000 to $238,000 \mathrm{~km}^{2}$, corresponding to $31 \%$ of the global built-up surface (Figure 4).

These exposure figures are essential variables that are used in the risk equation combined with building stock structural vulnerability within a given area to modulate the shaking intensity and ultimately define the risk of losses.
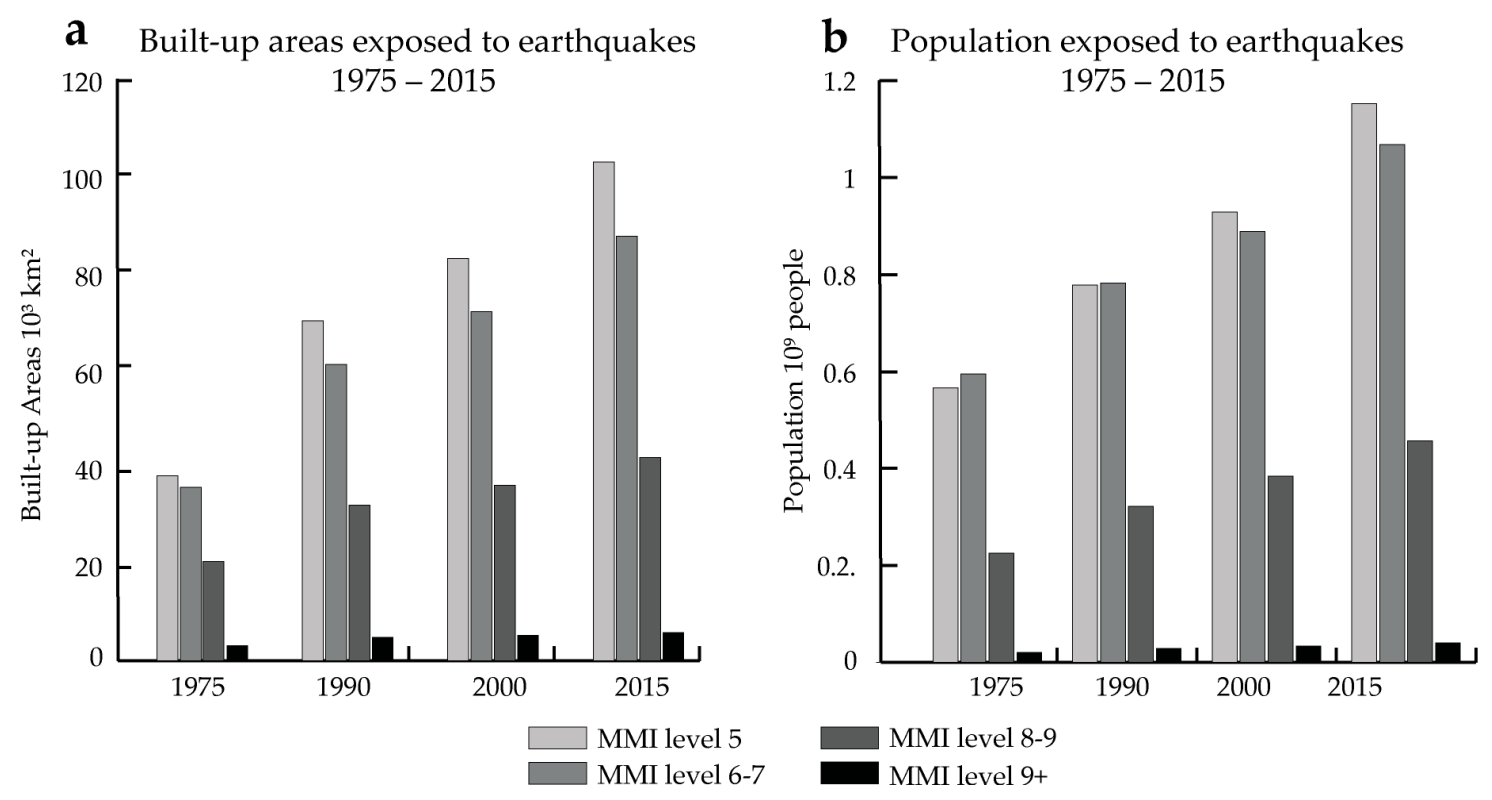

Figure 4. Built-up area (a) and population (b) in areas potentially affected by earthquakes of magnitude 5 and above based on a 475 probabilistic earthquake shaking intensity map measured in Modified Mercalli Intensity (MMI) scale.

Tsunamis are directly related to the earthquake magnitude as they propagate the seismic energy across water bodies. Tsunamis may impact areas already affected by seismic shaking and they are typically limited to the low-lying coastal zones in seismic regions. However, as tsunamis energy is propagated through waters across oceans, they can impact low elevation coastal zones in distant regions completely disconnected from the seismic event that originated the waves (e.g., the South Indian Ocean earthquake of 2004 that impacted the coast of Sri Lanka). Tsunami potentially affected areas are relatively smaller when compared to that of the earthquakes. Figure 5 shows that, in 2015, over 40 million people and $6500 \mathrm{~km}^{2}$ of built-up are potentially affected by tsunamis. When compared to the exposure of 1975, areas and population exposed to tsunamis have increased respectively by $40 \%$ and $70 \%$. Tsunamis show the lowest figures of exposure among those considered in this work (Figure 3). 


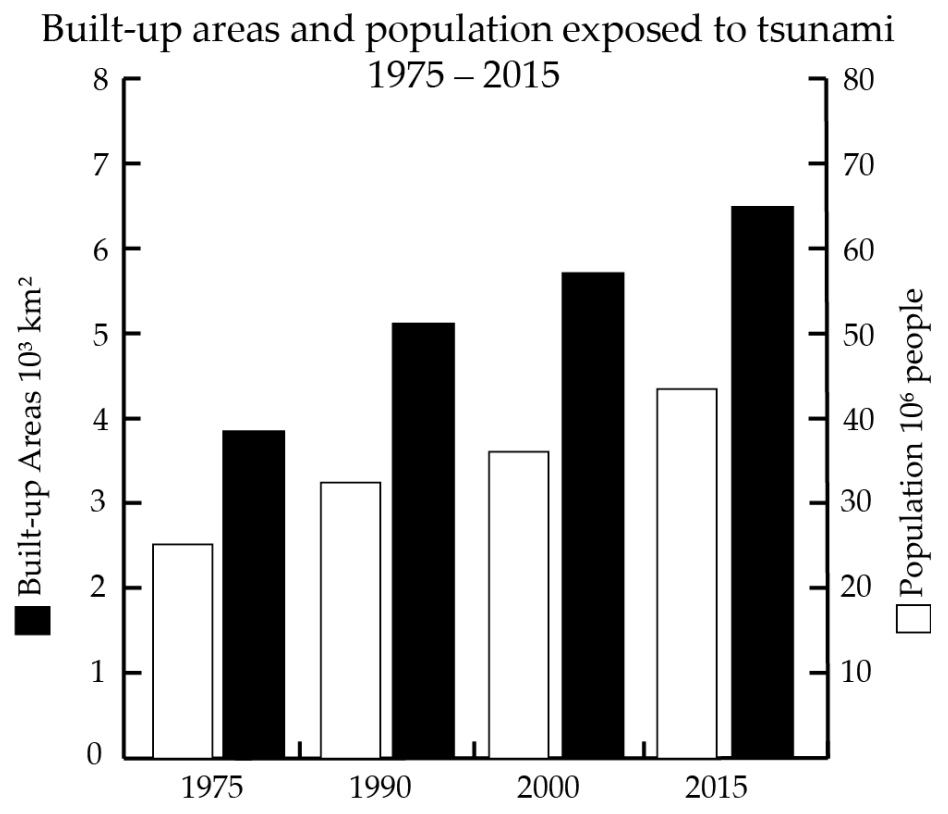

Figure 5. Built-up area (left) and population (right) in areas potentially affected by tsunamis Run-up and inundation.

\subsubsection{Exposure to Cyclone Winds and Sea Level Surge}

Cyclones and sea level surge are strictly related as the increased air pressure on the ocean generates the surge. The cyclone winds reaching the category 1 and 2 (Cw_S1-2) potentially affects regions that are inhabited by one billion people; while the hazard areas of cyclone winds exceeding category 3 (Cw_S3-5) cover regions inhabited by 600 million people in 2015 (Figure 6). That population exposed has doubled between 1975 and 2015. In 2015, built-up area exposed to cyclone winds was estimated at $110,000 \mathrm{~km}^{2}$ in class Cw_S1-2, while it was $70,000 \mathrm{~km}^{2}$ in class Cw_S3-5.
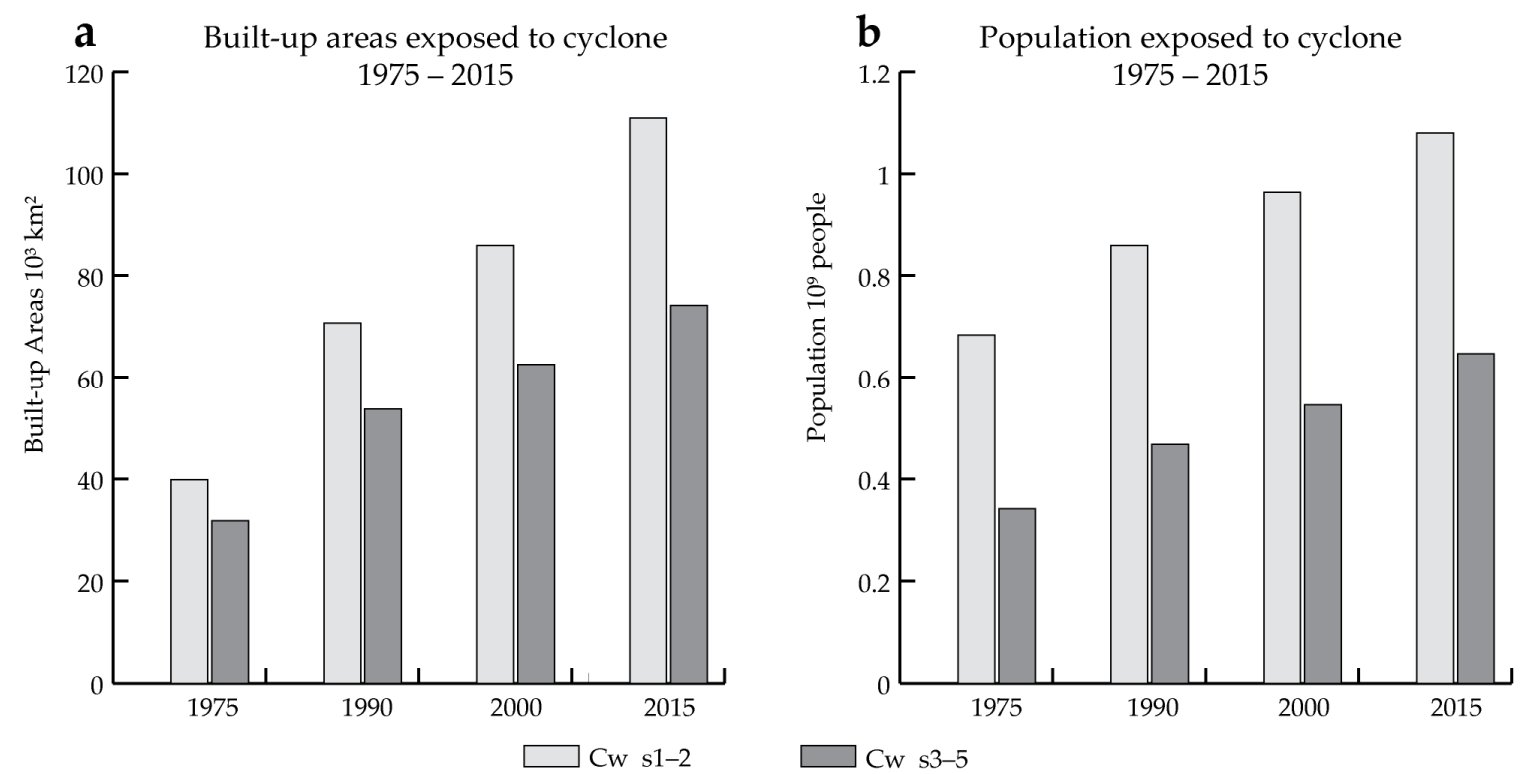

Figure 6. Built-up area (a) and population (b) in regions in which the cyclone winds may reach category 1 and 2 (Cw_1-2), and exceed category $3\left(\mathrm{Cw}_{-}\right.$3-5) based on a probabilistic hazard assessment with return period of 250 years. 
The sea level surge generally affects low elevated coastal areas in tropical regions where tropical cyclones occur. In fact, our analysis shows that, in 2015, sea level surge globally exposes approximately 160 million people. This figure is eight times smaller than cyclone winds exposure (Figure 7). Built-up area exposed in 2015 to sea level surge exceeds $25,000 \mathrm{~km}^{2}$. This figure has doubled since 1975 (Figure 7).

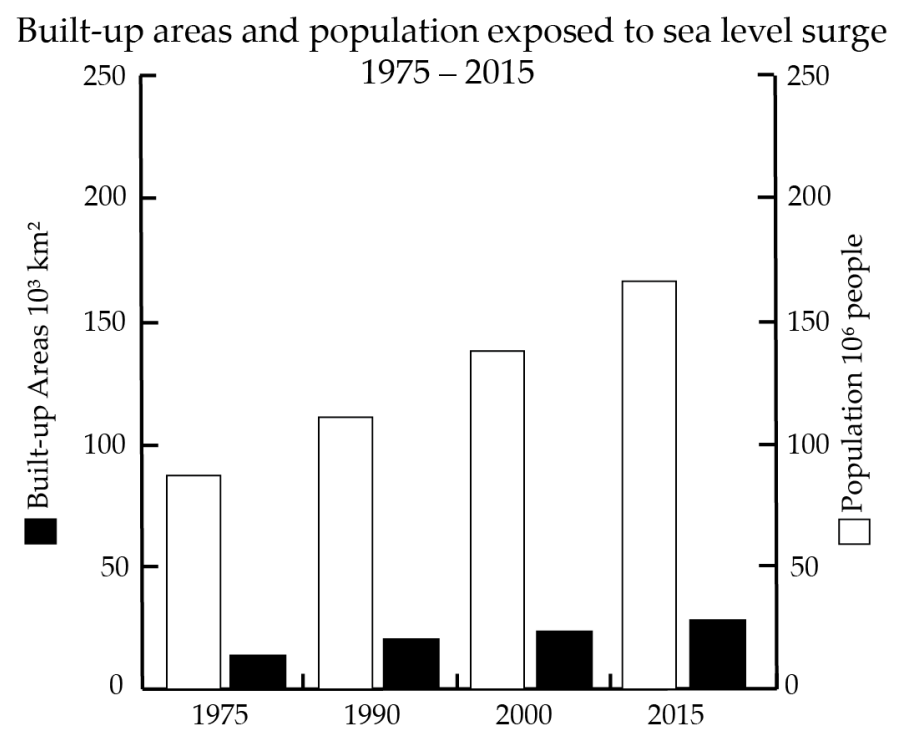

Figure 7. Built-up area and population in areas prone to seal level rise based on a probabilistic hazard assessment from cyclones with return period of 250 years.

\subsubsection{Exposure to Floods}

Flood is the hazard that affects most people globally [48]. This is due to a combination of extent of the flood prone areas in the world and the relative frequent return period associated with the hazard. Our analysis shows that in 2015 the population exposed exceeded one billion people (Figure 8) and the built-up area exposed approximates $80,000 \mathrm{~km}^{2}$. Both built-up area and population figures have more than doubled since the 1975 .

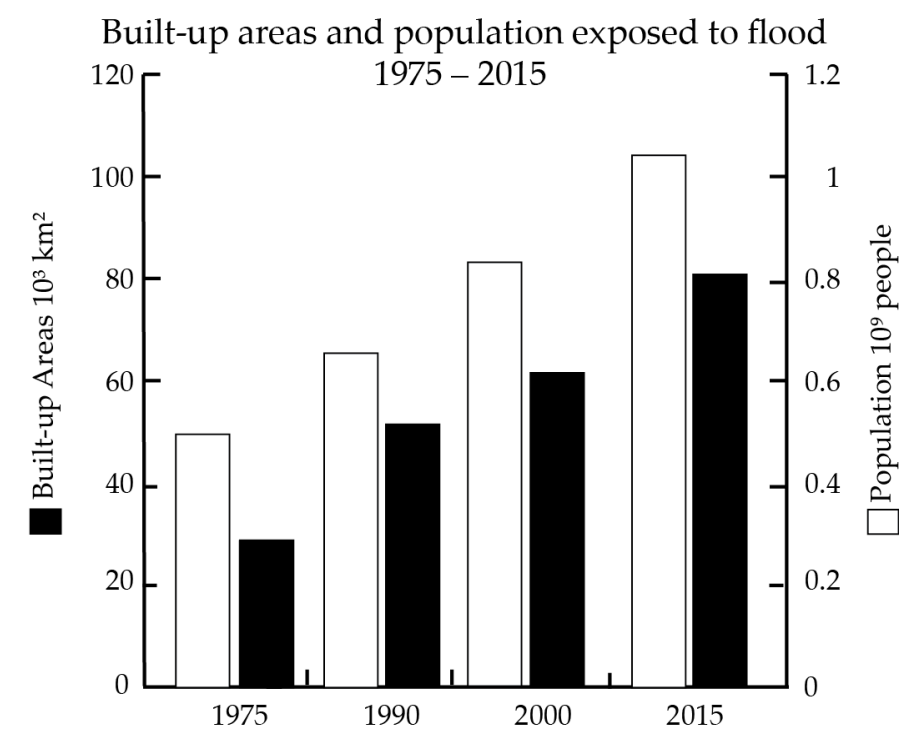

Figure 8. Built-up area and population in areas prone to flood based on a probabilistic hazard assessment from floods with return period of 100 years. 


\subsection{Spatio-Temporal Trends in Exposure}

The statistics generated from the datasets can be used to derive trends in exposed population. This work cannot provide a detailed insight on the trends of exposure but only an overview through a comparative analysis of the change in exposed people at national level. Although this research was not implemented with a multi-hazard perspective, the figures helps to understand the patterns of relative change in exposed population between 1990 and 2015 to the five selected hazards. We used the 25 year span from 1990 to 2015 that we consider the most reliable and suitable data for comparison purposes.

Figure 9 and Table 3 show the frequency of change in population exposure per country for each hazard between 1990 and 2015. The change is computed in classes of $25 \%$ change starting from the year 1990. The change ranges between $-100 \%$ and above $200 \%$. Figure 9 also shows the corresponding geographical distribution of change per country on a global map. Overall, exposure to earthquakes has increased in 123 out of the 145 exposed countries, and most importantly it has more than doubled in 21 countries located in Eastern, Southern, and Central Africa and in Central and West Asia. In 43 countries, the exposed population increased between $25 \%$ and $50 \%$. The decrease of less than $25 \%$ is recorded for 21 of the 22 countries.

Exposure to tsunamis has increased in 80 of the 97 exposed countries. Most importantly, the people exposed to tsunami increased by more than $200 \%$ in over 10 countries located in Asia (i.e., Cambodia, and Bangladesh), Latin America and the Caribbean (i.e., Venezuela and Brazil), and Africa. The exposure to cyclone winds has increased in 42 out of 46 countries. People exposure to cyclone wind doubled in seven countries mostly located in Latin America and Caribbean region. Exposure to storm surge increased in 71 out of the 78 countries reported. Most of the increase occurs in classes of 0 to 100 .

Table 3. Number of countries in the corresponding class of population change (\%), in areas exposed to the selected hazards between 1990 and 2015.

\begin{tabular}{cccccc}
\hline Frequency Change Class (\%) & $\begin{array}{c}\text { Earthquake } \\
(\mathbf{E q})\end{array}$ & $\begin{array}{c}\text { Tsunami } \\
\text { (Ts) }\end{array}$ & $\begin{array}{c}\text { Cyclone Wind } \\
(\mathbf{C w})\end{array}$ & $\begin{array}{c}\text { Storm Surge } \\
\text { (Ss) }\end{array}$ & $\begin{array}{c}\text { Floods } \\
\text { (Fl) }\end{array}$ \\
\hline$-100-75$ & 0 & 2 & 1 & 0 & 0 \\
$-75-50$ & 0 & 2 & 1 & 0 & 1 \\
$-50-25$ & 1 & 3 & 1 & 1 & 3 \\
$-25-0$ & 21 & 10 & 1 & 6 & 14 \\
$0-25$ & 28 & 16 & 12 & 11 & 28 \\
$25-50$ & 43 & 13 & 12 & 15 & 34 \\
$50-75$ & 21 & 19 & 6 & 12 & 27 \\
$75-100$ & 10 & 5 & 5 & 13 & 15 \\
$100-125$ & 8 & 6 & 3 & 5 & 12 \\
$125-150$ & 5 & 4 & 1 & 7 & 9 \\
$150-175$ & 2 & 3 & 1 & 2 & 4 \\
$175-200$ & 2 & 2 & 2 & 0 & 3 \\
$>200$ & 4 & 12 & 0 & 6 & 5 \\
Number of countries accounting & 145 & 97 & 46 & 78 & 155 \\
exposed population & & & & & 7 \\
\hline
\end{tabular}



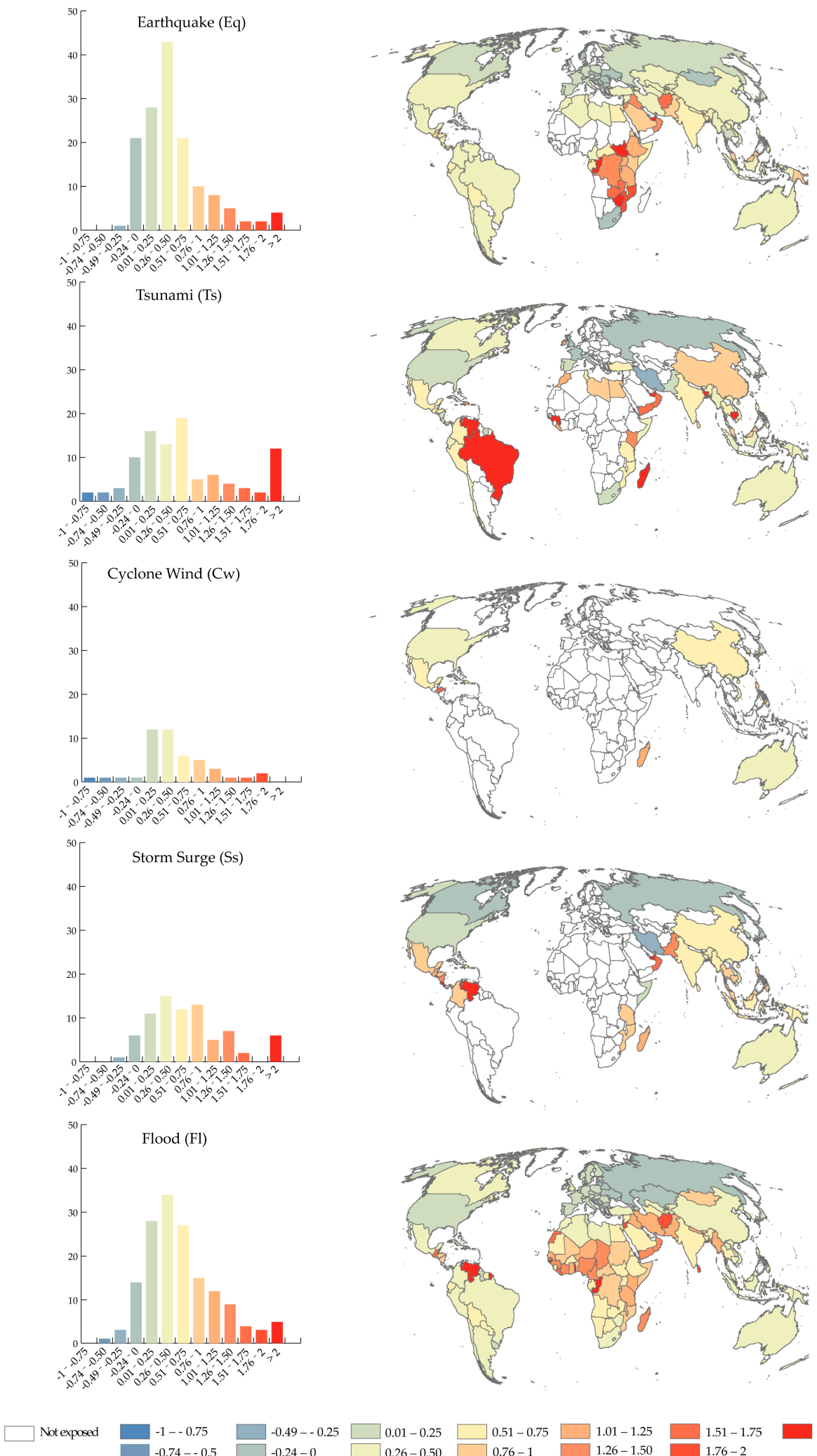

$\square 0.01-0.25$

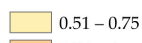

$75 \square 1.01-1.25$

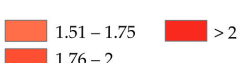

Figure 9. Frequency distributions (bar charts) and corresponding geographic representation of countries-excluding small islands-with population exposure changes. Changes refer to the period $1990-2015$, and the classes of change with $25 \%$ intervals range between $-100 \%$ and $200 \%$. 
Exposure to flood has increased in 137 of the 155 countries. Flood is the natural hazard exposing the highest number of countries (155), and most frequent exposed population is in the range $25-50 \%$ accounting 34 countries across Asia (13), Africa (8), Latin America and the Caribbean (7), Oceania (3), and Europe (2).

Overall, population exposed to the five selected natural hazards increased: up to $25 \%$ in 95 countries, between $25 \%$ and $50 \%$ in 117 , and between $50 \%$ and $75 \%$ in 85 , and it more than doubled in 100 countries. Considering all hazards together there has been also a decrease, mostly moderate (between 0 and $-25 \%$ ) in 52 countries.

The highest absolute population exposure increase (above $200 \%$ ) is recorded for six counties including Venezuela and the Republic of Congo, considerable increase in exposure (more than doubled between 1990 and 2015) occurred in 28 countries across: Africa (14 counties including: Liberia, Guinea, Cameroon), Asia (12 including: Sri Lanka, Afghanistan, Myanmar), and Latin America and the Caribbean (two including, Guatemala and Belize). The highest changes in exposed population (above $200 \%$ ) is recorded for six countries of which three are in the Latin America and Caribbean region (Venezuela, El Salvador, and Costa Rica).

In Figure 10, built-up areas and population dynamics in exposed areas are compared to those in areas not exposed to the five natural hazards over the 1975-2015 time span. In general terms, pattern of increase in exposure follow national dynamics of spatial expansion and population growth, which also takes place in hazard areas. However, trends between built-up and population differ. For all hazards-except floods-the relative growth of built-up areas has been lower than in areas not exposed to the hazards, while the relative growth of population has been higher than that in non-exposed areas with the exception of Tsunamis. Population in areas exposed to earthquakes of magnitude 5 and above in MMI scale increased by more than $90 \%$ while that in not exposed areas increased by more than $70 \%$; similarly growth occurred in areas exposed to cyclones (nearly $90 \%$ and $80 \%$ respectively), sea level surge (more than $90 \%$ and $80 \%$, respectively) and flood (doubling and by almost $80 \%$ respectively). The cases of reduction of exposed population are frequently associated to national demographic decline, principally in Eastern Europe.

Built-up areas and population change in areas exposed and not exposed to selected natural hazards $1975-2015$

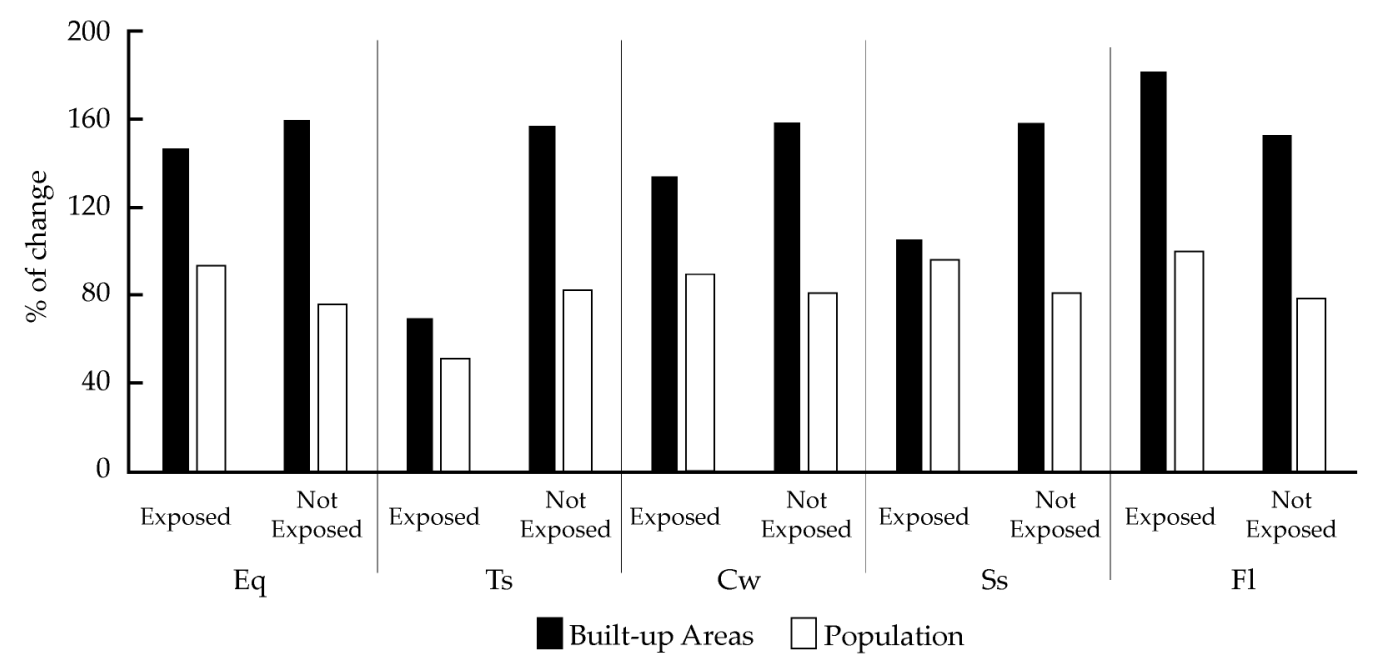

Figure 10. Comparison of relative changes of built-up areas and population respectively exposed and not exposed to the five selected natural hazards between 1975 and 2015. 


\section{Discussion}

The results presented in the previous sections are a systematic, global, and multi-temporal analysis of exposure of people and built-up areas to five natural hazards for selected returns periods. The probabilistic hazard assessment is based on the calculation of the spatial extent of the hazard intensity for that given return period. The assessment relies on evidence from past events recordings and from hypothesis on the distribution of the events derived from available knowledge. The hazard maps are thus the results of models that can be revised in time with the accumulation of new knowledge. For hazards with long return periods, the spatial hazard maps are typically more imprecise as historical events may have been documented with qualitative description rather than quantitative measurements. The most recent hazardous events are quantified more precisely and the measurements help to generate hazard maps with a higher degree of accuracy. The spatial extent of the hazard is thus a source of variation in the measurement of exposure.

The hazard datasets used in this research were generated with one return period per hazard as defined by the hazard community: 475 years for tsunami and earthquake; 250 years for cyclones and surge as available from the Global Assessment Report [1]. The difference in return periods relates to the nature of the processes that generate the hazard. For floods we have chosen to use the 100 year return period, among other return periods. Indicative flood maps are produced nationally to support disaster risk mitigation measures and are communicated to decision makers [47]. Risk assessment is typically conducted for multiple return periods; however, this paper focuses on the analysis of change in exposure in time for a given return period, due to the dynamics of human settlements. Further analyzes to characterize patterns of change could follow this exploratory attempt. This work is also not a multi-hazard assessment that would require an analysis of the cascading effects between related hazard (i.e., earthquakes and tsunamis) and/or the overlaps between hazard (i.e., cyclone winds and floods) and that would have required a different research design. Hazards may also change severity, intensity, duration, and thus return periods. Risk assessment would need to take this into account. However, the research aims also to show that it is possible to monitor the change in exposure in function of the changes in the characteristics of human settlements (spatial extension and demography) that ultimately are the essential variables to be used in risk analysis.

The measure of built-up area and population are "essential variables" that provide the spatial extent of the exposed physical assets and residential population that is linked to these physical constructed elements. The built-up area is a relatively crude measure of physical exposure as it defines its spatial location only. More precise physical exposure would require attribute information that includes for example the structural characteristics of the built-up area and its volume [7]. That information can then be used to attach built-up associate attributes. That investigation of global attributes of built-up is to be addressed in future analysis.

The novelty in the built-up area and population density maps in hazard prone areas produced within this research is its global coverage and the consistency of the built-up spatial extent in space and over time. That comes with using satellite remote sensing that records systematically over time. The second novelty is the production of detailed multi-temporal population grids. In fact, most people currently live and work in and around buildings. Local-level analyses would greatly benefit from differentiation into residential areas where people spend time in the night with commercial or industrial areas where people spend time during the day. However, having population disaggregated to all buildings (as in GHS-POP) may be more suitable for assessing exposure to probabilistic hazard layers whose disastrous events may occur either during night-time or day-time, or even span these two periods (e.g., in case of cyclones and floods).

Even though there are challenges, errors, and uncertainties associated with modeling the multi-temporal distribution of global population, these tend to decrease with time (i.e., towards current epochs) and are greatly mitigated in this work by adopting the country level as the most detailed scale of analysis for reporting results. While other global population grids do exist, GHS-POP 
currently constitutes the most detailed and consistent time series of population distribution data spanning the last 40 years, enabling assessment of changes in exposure in this period.

The quality assessment of GHS-BUILT initiated with [29], was expanded in [49], and now includes comparison with other information products [50,51]. This initial comparison identifies the GHS products as ' $\ldots$ one of the most reliable global, open and free data available to estimate built-up area' [51]. The global reference data for built up that could be used for a more thorough evaluation of the quality of all global built up layers has started to be produced as a cooperation between different research centers (https:/ /www.geo-wiki.org/branches/urban).

The Global Human Settlement Layers, GHS-BUILT and GHS-POP, are the key exposure layers for use in understanding risk as advocated by the Sendai Framework for Disaster Risk Reduction (DRR) Priority one [2]. Global exposure layers were introduced within the seismic community to assess seismic risk [52]. Exposure includes all the elements valued by society that can be harmed by hazard impact and most of societal valued assets are located within settlements. We refer to "exposure to hazard $n$ " to indicate the geographical area where the occurrence of a hazard is likely to strike.

The assessment of exposure to a given hazard depends on the quality of the hazard information and to the nature of the hazard that may change as the processes that generate the hazard may evolve in time. Hazard maps are produced to the best knowledge available at a given moment in time. The events of the 2011 Christchurch earthquake in New Zealand that occurred in an area not mapped as seismic zone, shows that hazard maps even in high income and data rich countries may not be up to date and may not precisely delineate the extent of the hazards. The improvement of hazard maps and exposure maps is the results of models and incremental improvement in knowledge. The continuous building up of knowledge is the essential process for making more precise risks assessments, a pre-condition for implementing better disaster risk reduction measures. The discussion of exposure and increase in exposure in this paper is based on producing statistics at the national level, as crisis management strategies are defined at the national level.

The statistics generated in this paper should thus be used in the proper context. The user of these data should be aware of their limitations that are largely due to the quality of the input data and the purpose for which these data were produced. For example, global hazard datasets are the results of models that return data at coarse resolution that include a number of assumptions. For example, the conversion from seismic intensity to shaking intensity developed by [43] may need be revised to obtain an association between earthquake magnitude and epicenter and shaking over landscapes, tested over a larger number of geographical areas than that available for this research. In addition, the shaking is reported for coarse grids of $5 \times 5 \mathrm{~km}$ cells. For operational and crisis management purposes the shaking should be refined to finer spatial units that better reflect the geological and soil properties that modulate the shaking. For coastal inundation models an improved digital elevation model may overcome the shortcomings available from the Digital Surface Model Shuttle Radar Topographic Mission (SRTM) as used for modeling the probabilistic Tsunami and Sea Level Surge hazard maps. SRTM for example includes all elevation surfaces including tree canopies and building heights, and in addition it is not extensively validated to provide error estimates that can be used at local level.

The built-up layer is the result of an image classification algorithm applied globally. That produces built-up area information that is consistent in time and space. However, for crisis management support at local level, satellite data at higher resolution should be used and the processing should be targeted to obtain optimal results for that location. In fact, the paper calls for finer scale analysis especially for the areas that need to generate operational disaster risk scenarios or to support crisis management activities.

The GHSL image processing framework is suited to combine newly generated human settlement maps produced from finer resolution imagery and to combine it with hazard maps resulting from an improved spatial resolution and improved hazard models that will be available in the future. The data 
can be analyzed up to city scale as is available in gridded form and thus allow to aggregate statistic for spatial unit bigger than the cell.

\section{Conclusions}

This work combines five open source global hazard maps with the global built-up and population available for the last 40 years to analyze changes in exposure over time. It does not aim to provide an ultimate figure of exposure to the different hazards, but rather to raise the attention of the extraordinary increase in built-up and population as a key driver of disaster risk.

This work is foremost a methodological and data exploration exercise as we are testing datasets derived from remote sensing data. The hazard maps are the results of research in the hazard scientific communities. The global hazard maps are the best knowledge to date and are being continuously updated with new observation and new modeling that aim to capture the changing nature of climate. Future exposure will need to incorporate the changes in these hazard maps.

The GHS built-up is the only open and free multi-temporal global exposure dataset available to date. The data are generated from remote sensing Landsat archive based on information extraction procedure on association analysis used to produce the first global multi-temporal built-up layers. New image extraction techniques and most importantly new global finer scale resolution remote sensing datasets are likely to produce improved global built-up maps and derived residential population data. These data are sufficiently detailed to be used in disaster risk assessment, early warning models, and as a system of indicators used by policy makers.

This is also a call for exploiting better remote sensing and geospatial datasets for use in risk modeling. For example, (i) elevation data needs to be improved especially to identify the low elevated coastal zones subject to sea level surge, tsunamis, and the expected centennial and millennial sea level rise; (ii) global archives of fine scale satellite imagery should be used to produce very high resolution exposure data that include (ideally) also the height of the built-up area, as well as socio economic variables including gender, age, income for better assessing vulnerability as addressed within the Sendai FDRR [2] and the SDGs [53].

This work is an initial assessment of global exposure. This research aims to contribute to understanding global risk through a single hazard analysis of exposure. Future work should address across hazard analysis with hazard computed with different return periods. Future work should also address multi-hazard exposure that explores the cascading effects between hazards that were not addressed herein. In this research, we start to get a global picture that needs to be refined in different ways. The nearly doubling of exposure over forty years may be used to assess risks and infer policy strategies. In fact, the risk may be mitigated only when measures of vulnerability reduction, hazard mitigation, and preparedness to hazard impact have been put in place. Policy makers may use these figures to frame the magnitude of the risk. Risk reduction practitioners may use the open data to quantify disaster risk at the local level from where the disaster risk reduction should begin.

Finally, exposure will likely continue to growth with the increase in population and increase of the built environment that comes with economic development. For 2050, the population is projected to grow by 1.5 billion and the built-up area is likely to increase at a rate higher to that of the past 40 years. These are figures to urgently act upon if the targets of the Sendai Framework for Disaster Risk reduction are to be achieved.

Author Contributions: This work was a joint effort of many authors and the contribution of each author is as follows: Conceptualization, M.P. and D.E.; Methodology, M.P. and A.J.F.; Software, A.J.F.; Validation, M.M., C.C., S.F. and M.S.; Formal Analysis, A.J.F, M.M., A.S; Data Curation, M.M., A.J.F.; Writing-Original Draft Preparation, D.E.; Writing-Review \& Editing, D.E., M.M., S.F., A.J.F., C.C., M.S.; Supervision, T.K.

Funding: This research received no external funding.

Conflicts of Interest: The authors declare no conflict of interest. 


\section{References}

1. United Nations Office for Disaster Risk Reduction (UNISDR). Global Assessment Report 2015; United Nations: Geneva, Switzerland, 2015.

2. United Nations Office for Disaster Risk Reduction (UNISDR). Sendai Framework for Disaster Risk Reduction 2015-2030; United Nations International Strategy for Disaster Risk Reduction: Geneva, Switzerland, 2015.

3. United Nations Treaty Collection "Paris Agreement”, Chapter XXVII 7.d. Available online: https://treaties.un. org/doc/Treaties/2016/02/20160215\%2006-03\%20PM/Ch_XXVII-7-d.pdf (accessed on 12 December 2015).

4. United Nations. Habitat III New Urban Agenda; United Nations: Geneva, Switzerland, 2016.

5. Cardona, O.D.; van Aalst, M.K.; Birkmann, J.; Fordham, M.; McGregor, G.; Perez, R.; Pulwarty, R.S.; Schipper, E.L.F.; Sinh, B.T.; Decamps, H.; et al. Determinants of risk: Exposure and vulnerability. In Managing the Risks of Extreme Events and Disasters to Advance Climate Change Adaptation; Cambridge University Press: Cambridge, UK, 2012; pp. 65-108.

6. Turner, B.L.; Kasperson, R.E.; Matson, P.A.; McCarthy, J.J.; Corell, R.W.; Christensen, L.; Eckley, N.; Kasperson, J.X.; Luers, A.; Martello, M.L.; et al. A framework for vulnerability analysis in sustainability science. Proc. Natl. Acad. Sci. USA 2003, 100, 8074-8079. [CrossRef] [PubMed]

7. Ehrlich, D.; Kemper, T.; Blaes, X.; Soille, P. Extracting building stock information from optical satellite imagery for mapping earthquake exposure and its vulnerability. Nat. Hazards 2013, 68, 79-95. [CrossRef]

8. Dilley, M.; Chen, R.S.; Deichmann, U.; Lam, A.L.L.; Arnold, M. Natural Disaster Hotspots A Global Risk Analysis; World Bank: Washington, DC, USA, 2005.

9. Loveland, T.R.; Reed, B.C.; Brown, J.F.; Ohlen, D.O.; Zhu, Z.; Yang, L.; Merchant, J.W. Development of a global land cover characteristics database and IGBP DISCover from $1 \mathrm{~km}$ AVHRR data. Int. J. Remote Sens. 2000, 21, 1303-1330. [CrossRef]

10. Sutton, P.; Roberts, D.; Elvidge, C.; Baugh, K. Census from Heaven: An estimate of the global human population using night-time satellite imagery. Int. J. Remote Sens. 2001, 22, 3061-3076. [CrossRef]

11. Schneider, A.; Friedl, M.A.; Potere, D. Mapping global urban areas using MODIS 500-m data: New methods and datasets based on 'urban ecoregions'. Remote Sens. Environ. 2010, 114, 1733-1746. [CrossRef]

12. Esch, T.; Marconcini, M.; Felbier, A.; Roth, A.; Heldens, W.; Huber, M.; Schwinger, M.; Taubenböck, H.; Müller, A.; Dech, S. Urban Footprint Processor-Fully Automated Processing Chain Generating Settlement Masks from Global Data of the TanDEM-X Mission. IEEE Geosci. Remote Sens. Lett. 2013, 10, 1617-1621. [CrossRef]

13. Gong, P.; Wang, J.; Yu, L.; Zhao, Y.C.; Zhao, Y.Y.; Liang, L.; Niu, Z.; Huang, X.; Fu, H.; Liu, S.; et al. Finer resolution observation and monitoring of global land cover: First mapping results with Landsat TM and ETM+ data. Int. J. Remote Sens. 2013, 34, 2607-2654. [CrossRef]

14. World Bank. East Asia's Changing Urban Landscape: Measuring a Decade of Spatial Growth; World Bank: Washington, DC, USA, 2015.

15. Srinivasan, V.; Seto, K.C.; Emerson, R.; Gorelick, S.M. The impact of urbanization on water vulnerability: A coupled human-environment system approach for Chennai, India. Glob. Environ. Chang. 2013, 23, 229-239. [CrossRef]

16. Mertes, C.M.; Schneider, A.; Sulla-Menashe, D.; Tatem, A.J.; Tan, B. Detecting change in urban areas at continental scales with MODIS data. Remote Sens. Environ. 2015, 158, 331-347. [CrossRef]

17. Taubenböck, H.; Esch, T.; Felbier, A.; Wiesner, M.; Roth, A.; Dech, S. Monitoring urbanization in mega cities from space. Remote Sens. Environ. 2012, 117, 162-176. [CrossRef]

18. Melchiorri, M.; Florczyk, A.; Freire, S.; Schiavina, M.; Pesaresi, M.; Kemper, T. Unveiling 25 Years of Planetary Urbanization with Remote Sensing: Perspectives from the Global Human Settlement Layer. Remote Sens. 2018, 10, 768. [CrossRef]

19. Ban, Y.; Gong, P.; Giri, C. Global land cover mapping using Earth observation satellite data: Recent progresses and challenges. ISPRS J. Photogramm. Remote Sens. 2015, 103, 1-6. [CrossRef]

20. Riedel, I.; Guéguen, P.; Mura, M.D.; Pathier, E.; Leduc, T.; Chanussot, J. Seismic vulnerability assessment of urban environments in moderate-to-low seismic hazard regions using association rule learning and support vector machine methods. Nat. Hazards 2015, 76, 1111-1141. [CrossRef] 
21. Sahar, L.; Muthukumar, S.; French, S.P. Using Aerial Imagery and GIS in Automated Building Footprint Extraction and Shape Recognition for Earthquake Risk Assessment of Urban Inventories. IEEE Trans. Geosci. Remote Sens. 2010, 48, 3511-3520. [CrossRef]

22. Sarabandi, P.; Kiremidjian, A.S. Development of Algorithms for Building Inventory Compilation through Remote Sensing and Statistical Inferencing; John A. Blume Earthquake Envineering Center, Standford University: Standford, CA, USA, 2007.

23. Geiß, C.; Taubenböck, H. One step back for a leap forward: Toward operational measurements of elements at risk. Nat. Hazards 2017, 86, 1-6. [CrossRef]

24. Wieland, M.; Pittore, M.; Parolai, S.; Zschau, J. Exposure Estimation from Multi-Resolution Optical Satellite Imagery for Seismic Risk Assessment. ISPRS Int. J. Geo-Inf. 2012, 1, 69-88. [CrossRef]

25. Wieland, M.; Pittore, M.; Parolai, S.; Tyagunov, S. A Multiscale Exposure Model for Seismic Risk Assessment in Central Asia. Seismol. Res. Lett. 2015, 86, 210-222. [CrossRef]

26. Wieland, M.; Pittore, M.; Parolai, S.; Zschau, J.; Moldobekov, B.; Begaliev, U. Estimating building inventory for rapid seismic vulnerability assessment: Towards an integrated approach based on multi-source imaging. Soil Dyn. Earthq. Eng. 2012, 36, 70-83. [CrossRef]

27. Wieland, M.; Pittore, M.; Parolai, S.; Begaliev, U.; Yasunov, P.; Niyazov, J.; Tyagunov, S.; Moldobekov, B.; Saidiy, S.; Ilyasov, I.; et al. Towards a cross-border exposure model for the Earthquake Model Central Asia. Ann. Geophys. 2015, 58, 1-8.

28. Geiß, C.; Schauß, A.; Riedlinger, T.; Dech, S.; Zelaya, C.; Guzmán, N.; Hube, M.A.; Arsanjani, J.J.; Taubenböck, H. Joint use of remote sensing data and volunteered geographic information for exposure estimation: Evidence from Valparaíso, Chile. Nat. Hazards 2017, 86, 81-105. [CrossRef]

29. Pesaresi, M.; Ehrlich, D.; Ferri, S.; Florczyk, A.; Carneiro, F.S.M.; Halkia, S.; Julea, A.M.; Kemper, T.; Soille, P.; Syrris, V. Operating Procedures for the Production of the Global Human Settlement Layer from Landsat Data of the Epochs 1975, 1990, 2000, and 2014; Joint Research Centre, Publications Office of the European Union: Luxembourg, 2016.

30. Pesaresi, M.; Syrris, V.; Julea, A. Analyzing big remote sensing data via symbolic machine learning. In Proceedings of the 2016 Conference on Big Data from Space, Santa Cruz de Tenerife, Spain, 15-17 March 2016; pp. 156-159.

31. Sergio, F.; MacManus, K.; Pesaresi, M.; Doxsey-Whitfield, E.; Mills, J. Development of new open and free multi-temporal global population grids at $250 \mathrm{~m}$ resolution. In Proceedings of the AGILE 2016, Helsinki, Finland, 14-17 June 2016.

32. Pesaresi, M.; Corbane, C.; Julea, A.; Florczyk, A.; Syrris, V.; Soille, P. Assessment of the Added-Value of Sentinel-2 for Detecting Built-up Areas. Remote Sens. 2016, 8, 299. [CrossRef]

33. Pesaresi, M.; Ehrlich, D.; Kemper, T.; Siragusa, A.; Florczyk, A.; Freire, S.; Corbane, C. Atlas of the Human Planet 2017: Global Exposure to Natural Hazards; Joint Research Centre, Publications Office of the European Union: Luxembourg, 2017.

34. Markham, B.L.; Helder, D.L. Forty-year calibrated record of earth-reflected radiance from Landsat: A review. Remote Sens. Environ. 2012, 122, 30-40. [CrossRef]

35. Woodcock, C.E.; Strahler, A.H. The factor of scale in remote sensing. Remote Sens. Environ. 1987, 21, 311-332. [CrossRef]

36. Gutman, G.; Huang, C.; Chander, G.; Noojipady, P.; Masek, J. Assessment of the NASA-USGS Global Land Survey (GLS) datasets. Remote Sens. Environ. 2013, 134, 249-265. [CrossRef]

37. Lu, D.; Weng, Q. A survey of image classification methods and techniques for improving classification performance. Int. J. Remote Sens. 2007, 28, 823-870. [CrossRef]

38. Pesaresi, M.; Syrris, V.; Julea, A. A new method for Earth Observation Data analyitics based on symbolic Machine learning. Remote Sens. 2016, 8, 399. [CrossRef]

39. Center for International Earth Science Information Network-CIESIN-Columbia University. Gridded Population of the World, Version 4 (GPWv4): Population Count, Revision 10; NASA Socioeconomic Data and Applications Center (SEDAC): Palisades, NY, USA, 2017.

40. Balk, D.L.; Deichmann, U.; Yetman, G.; Pozzi, F.; Hay, S.I.; Nelson, A. Determining Global Population Distribution: Methods, Applications and Data. In Advances in Parasitology; Elsevier: New York, NY, USA, 2006; Volume 62, pp. 119-156. 
41. Doxsey-Whitfield, E.; Macmanus, K.; Adamo, S.B.; Baptista, S.R. Taking Advantage of the Improved Availability of Census Data: A First Look at the Gridded Population of the World, Version 4. Pap. Appl. Geogr. 2015, 1, 226-234. [CrossRef]

42. Giardini, D.; Grünthal, G.; Shedlock, K.M.; Zhang, P. The GSHAP Global Seismic Hazard Map. Ann. Geophys. 1999, 42, 1233-1239.

43. Wald, D.J.; Quitoriano, V.; Heaton, T.H.; Kanamori, H. Relationships between Peak Ground Acceleration, Peak Ground Velocity, and Modified Mercalli Intensity in California. Earthq. Spectra 1999, 15, 557-564. [CrossRef]

44. Jarvis, A.; Reuter, H.I.; Guevara, E. Hole-Filled SRTM for the Globe Version 4. Available online: http: / / srtm.csi.cgiar.org (accessed on 1 June 2018).

45. Hoque, M.M.A.; Khan, S.A.M. Storm surge flooding in Chittagong city and associated risks. In Proceedings of the Destructive Water: Water-Caused Natural Disasters, Their Abatement and Control, Anaheim, CA, USA, 24-28 June 1996.

46. Dottori, F.; Salamon, P.; Bianchi, A.; Alfieri, L.; Hirpa, F.A.; Feyen, L. Development and evaluation of a framework for global flood hazard mapping. Adv. Water Resour. 2016, 94, 87-102. [CrossRef]

47. Hall, J.W.; Sayers, P.B.; Dawson, R.J. National-scale Assessment of Current and Future Flood Risk in England and Wales. Nat. Hazards 2005, 36, 147-164. [CrossRef]

48. Centre for Research on the Epidemeology of Disasters and United Nations International Strategy for Diasaster Reduction. The Human Cost of Weather Related Disasters; Universite' Catolique de Louvain: Brussels, Belgium, 2015.

49. Leyk, S.; Uhl, J.H.; Balk, D.; Jones, B. Assessing the accuracy of multi-temporal built-up land layers across rural-urban trajectories in the United States. Remote Sens. Environ. 2018, 204, 898-917. [CrossRef] [PubMed]

50. Klotz, M.; Kemper, T.; Geiß, C.; Esch, T.; Taubenböck, H. Mapping spatial settlement patterns on a global scale: Multi-scale cross-comparison of new and existing global urban maps. Remote Sens. Environ. 2015, 178, 191-212. [CrossRef]

51. Florczyk, A.J.; Melchiorri, M.; Politis, P.; Pesaresi, M.; Esch, T.; Ehrlich, D. Analysing Global Consensus on Mapping Human Settlements and Built-Up Area from Space. In Proceedings of the 7-th Digital Earth Summit, El Jadida, Morocco, 17-19 April 2018; pp. 97-102.

52. Dell'Acqua, F.; Gamba, P.; Jaiswal, K. Spatial aspects of building and population exposure data and their implications for global earthquake exposure modeling. Nat. Hazards 2013, 68, 1291-1309. [CrossRef]

53. UN General Assembly. Transforming Our World: The 2030 Agenda for Sustainable Development; United Nations: Geneva, Switzerland, 2015. 